\title{
Effects of Stiffener Type on Fatigue Resistance of Steel-UHPC Composite Bridge Decks
}

\author{
Xiugui Sun $\mathbb{D},{ }^{1}$ Jianhua $\mathrm{Hu} \mathbb{D},{ }^{2}$ Yu Li, ${ }^{3}$ and Guoping Huang $\mathbb{D}^{4}$ \\ ${ }^{1}$ Hunan University, Changsha 410082, China \\ ${ }^{2}$ Hunan Communication and Water Conservancy Group LTD., Changsha 410000, China \\ ${ }^{3}$ Hunan Provincial Communications Planning, Survey and Design Institute Co., Ltd., Changsha 410000, China \\ ${ }^{4}$ College of Civil Engineering, Hunan City University, Yiyang 413000, China \\ Correspondence should be addressed to Jianhua Hu; 402950468@qq.com and Guoping Huang; gphuang@hnu.edu.cn
}

Received 24 October 2021; Accepted 17 January 2022; Published 7 February 2022

Academic Editor: Lingkun Chen

Copyright $\odot 2022$ Xiugui Sun et al. This is an open access article distributed under the Creative Commons Attribution License, which permits unrestricted use, distribution, and reproduction in any medium, provided the original work is properly cited.

\begin{abstract}
Recent research showed that ultrahigh-performance concrete (UHPC) and orthotropic steel bridge decks could be integrated to form steel-UHPC composite sections offering superior load-carrying capacity and fatigue resistance. This study investigates the effects of longitudinal stiffener types on the fatigue resistance of steel-UHPC composite sections. Three types of longitudinal stiffeners were compared, including U-ribs, bulb flat ribs, and plate ribs. Finite element analysis and full-scale fatigue tests were performed to investigate the load-carrying capacity and fatigue resistance of the composite bridge decks with different stiffeners. Besides, the proposed steel-UHPC composite bridge decks were compared with conventional orthotropic steel decks. The results show that steel box girders with bulb flat rib composite deck have reasonable fatigue resistance, construction efficiency, and economic benefits. This study is expected to promote the design and evaluation of economic steel-UHPC composite bridge decks to achieve higher mechanical performance and long-term durability.
\end{abstract}

\section{Introduction}

Orthotropic steel decks (OSDs) have been widely used in long-span bridges to bear wheel loads. Conventional OSDs are composed of vertical and horizontal stiffeners and a top plate. The longitudinal rib can be categorized in two forms: open rib and closed rib. The two types of longitudinal ribs have different characteristics in mechanical performance, structural characteristics, applicable conditions, and so on. A large number of scholars have done intensive research on the two types of ribs in OSDs. With the same amount of steel used, the open ribs are often associated with lower torsional and flexural rigidity and stability of the OSD and the soclosed U-ribs have been widely used in conventional OSDs. However, the open ribs are easier to manufacture and construct than U-ribs that require much time for grooving and rolling. In addition, fillet welding can be adopted to weld open ribs on the steel top plate, avoiding partial penetration welding of the U-rib, which thus ensures the welding quality and better fatigue performance [1].
Engineering practice shows that fatigue and pavement damages are common in OSDs [2-4]. The damages are closely associated with the relatively low stiffness of the OSDs, in particular, the low local stiffness. Under mechanical loading, a high stress range can be generated in conventional OSDs and may significantly reduce the fatigue life of welded joints that are prone to fatigue. To enhance the fatigue resistance, Europe and Japan used composite decks to increase the stiffness and reduce the stress ranges. Compared with conventional OSDs, composite decks utilize a layer of reinforced concrete integrated with the steel deck plate via shear connectors, such as headed shear studs that are welded on the top surface of the steel place and embedded in the concrete deck.

While the use of composite sections increased the stiffness of the OSDs, the conventional composite decks have limitations. First, the concrete must be thick enough to deliver sufficient load-carrying capacity, and a thick concrete deck can significantly increase the deck weight. Second, the service life of reinforced concrete is limited because 
conventional concrete has low crack resistance and is brittle in tension. In real-life applications, there are many factors that can cause concrete cracking, such as thermal effects and shrinkage [5-7]. To address these limitations, ultrahighperformance concrete has been used to replace the conventional concrete in composite bridge decks [2]. The use of UHPC greatly improved the load-carrying capacity and the long-term durability $[8,9]$, due to its very high compressive strength, crack resistance, and dense microstructures [10-13]. The steel-UHPC composite deck system has been applied in many projects, such as the Zhuzhou Fengxi Bridge (a self-anchored suspension bridge with a main span of $300 \mathrm{~m}$ ) and the Yueyang Dongting Lake Bridge in China (a suspension bridge with a main span of $1480 \mathrm{~m}$ ). However, in the existing studies, U-ribs were used in the steel-UHPC composite OSDs. Engineering practices show that the rigidity of the bridge decks can be greatly enhanced by the use of steel-UHPC composite sections. Therefore, it is hypothesized that the rigidity of the stiffener is no longer the controlling factor of the rigidity of the bridge deck system. It is further postulated that the stiffener can be either open or closed. Currently, there is limited research on the performance and design of composite OSDs with open ribs [14-16].

This study aims to investigate the performance of steelUHPC composite OSD with open ribs. To this end, this study evaluates the effects of bulb flat ribs on the loadcarrying capacity and fatigue resistance of the composite OSD through finite element analysis and experimental testing. To ensure this research is practicable for engineering practices, the Xiangtan Zhaohua Xiangjiang River Bridge in China is taken as the background bridge structure. This study is expected to promote the design and evaluation of composite bridge decks to achieve higher mechanical performance and long-term durability.

\section{Description of the Bridge}

Figure 1 shows the Xiangtan Zhaohua Xiangjiang River Bridge, which is a single-tower, self-anchored, suspension bridge crossing the Xiangjiang River. It is a signature bridge of Xiangtan City in China, connecting the Zhaoshan District and the Jiuhua District. The layout of its span is $45 m+168 m+228 m+2 \times 45 m$, as depicted in Figure 2. The design grade is Urban Grade I Main Road, with II(2) navigation grade. The design speed of vehicles on the bridge is $60 \mathrm{~km} / \mathrm{h}$, and the width of the main stiffening beam of the bridge is $39.5 \mathrm{~m}$.

In regard to the bridge tower, a double-column structure was adopted, the elevation of the tower column is curved, and the overall shape is like a budding lotus flower. The height of the tower above the cap is $124.8 \mathrm{~m}$, with the tower column set with two beams. With respect to the main cable, the span layout is $163.1 \mathrm{~m}+223.1 \mathrm{~m}$. The transverse spacing of the main cable is $33.9 \mathrm{~m}$, and the single main cable is composed of 39 strands of steel cables. The main cable is constructed by prefabricated parallel steel cables one by one, each of which consists of 127 o $5.1 \mathrm{~mm}$ galvanized highstrength parallel steel wires. A total of 32 pairs of slings are

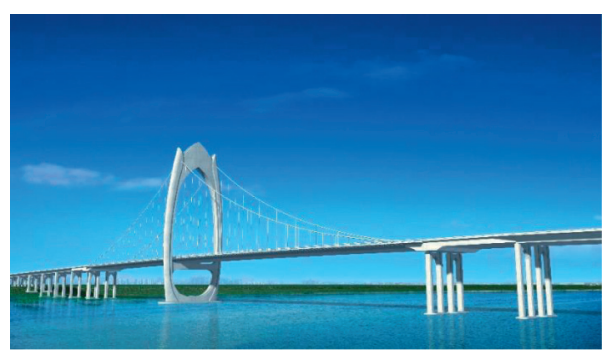

FIgURe 1: Depiction of the Xiangtan Zhaohua Xiangjiang River Bridge.

set in the whole bridge, the standard spacing of which is $10.8 \mathrm{~m}$.

The steel stiffening beam is a flat streamline box girder of a single box with three cells, with a total length of $377 \mathrm{~m}$, which is divided into 37 sections. The standard section is $10.8 \mathrm{~m}$ in length, and $195 \mathrm{~T}$ in weight. The thickness of the top plate of the girder is $12 \mathrm{~mm}$, and the top plate of the box girder is stiffened by the bulb flat ribs, which are $12 \mathrm{~mm}$ thick and $260 \mathrm{~mm}$ high, with a transverse spacing of $450 \mathrm{~mm}$. Headed shear studs $(\varphi 13 \times 40 \mathrm{~mm})$ were welded in the traffic area of the girder, with a spacing of $225 \mathrm{~mm} ; \varphi 10$ ribbed steel mesh is set in the UHPC layer, with a spacing of $37.5 \mathrm{~mm}$, and the $50 \mathrm{~mm}$ thick UHPC layer is steam cured at high temperature to form a composite deck system. The steel stiffening beam is shown in Figure 3.

\section{Composite Deck with the Open Rib}

This study attempts to design a steel-UHPC composite deck with plate ribs and a steel-UHPC composite deck with bulb flat ribs. Figure 4 shows a total of four types of composite OSDs investigated in this study, including (1) conventional composite OSD with a reinforced concrete deck and U-ribs; (2) steel-UHPC composite OSD with U-ribs, designated as UCD-U; (3) steel-UHPC composite OSD with bulb flat ribs, designated as UCD-B; and (4) steel-UHPC composite OSD with plate ribs, designated as UCD-P. The four types of OSDs are compared, in terms of flexural rigidity, steel consumption, and deck weight.

Based on the above four types of composite OSDs, eight different schemes of the composite section are proposed and investigated in this study, as listed in Table 1 . Scheme 1 is a conventional OSD without any concrete layer on the steel deck plate. Scheme 1 is used as the control to evaluate the other schemes. Compared with Scheme 1, Scheme 2 has a higher flexural rigidity and a lower steel consumption. Specifically, the flexural rigidity is increased by $22 \%$, and the steel consumption is reduced by $16 \%$, indicating that the use of a thin $(50 \mathrm{~mm})$ layer of UHPC can effectively increase the rigidity and also save steel. Schemes 3 to 5 show that adjusting the arrangement spacing of the bulb flat steel ribs can match the composite deck structures with different deck stiffness. Compared with Scheme 1, Schemes 3 to 5 achieve higher stiffness of the composite deck and a lower steel consumption; Schemes 6 to 8 show that adjusting the height and arrangement spacing of the plate ribs can match the 


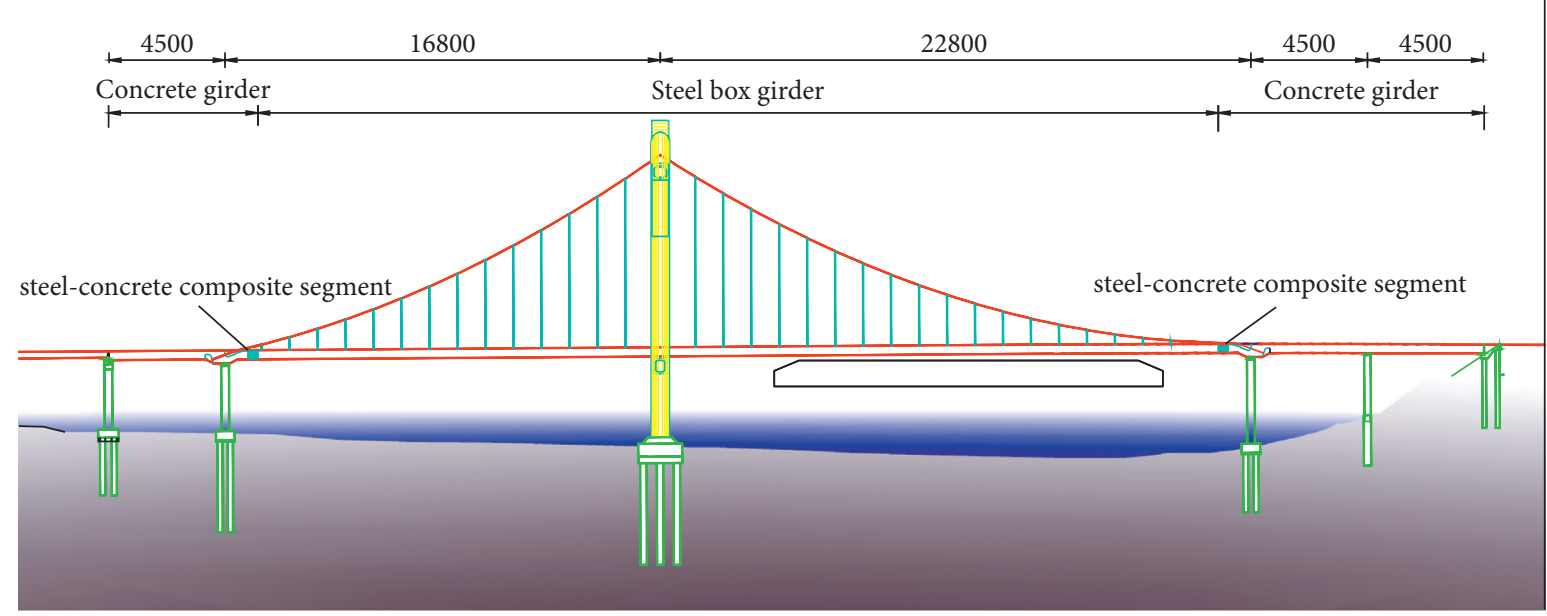

FIgURE 2: General layout of the Xiangtan Zhaohua Xiangjiang River Bridge (unit: $\mathrm{cm}$ ).

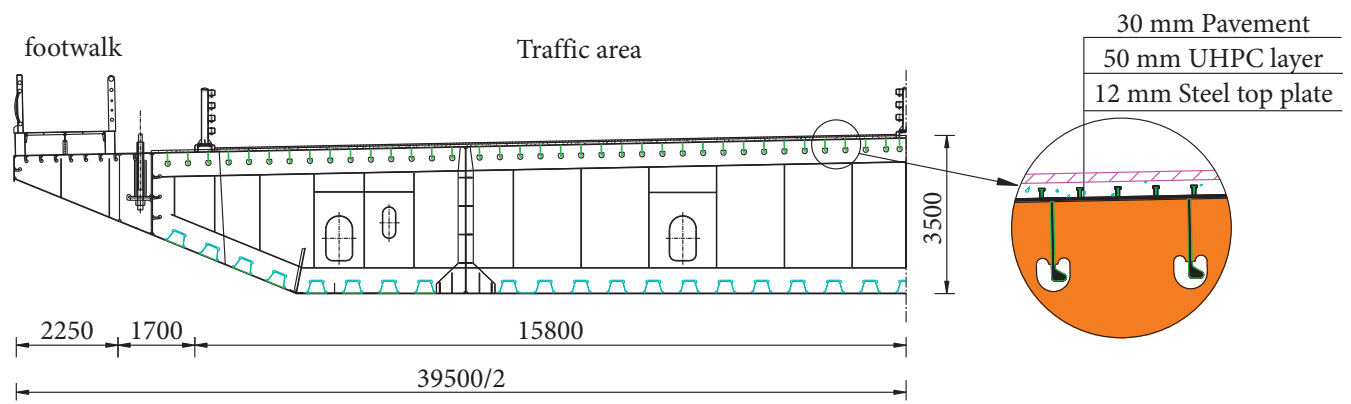

(a)

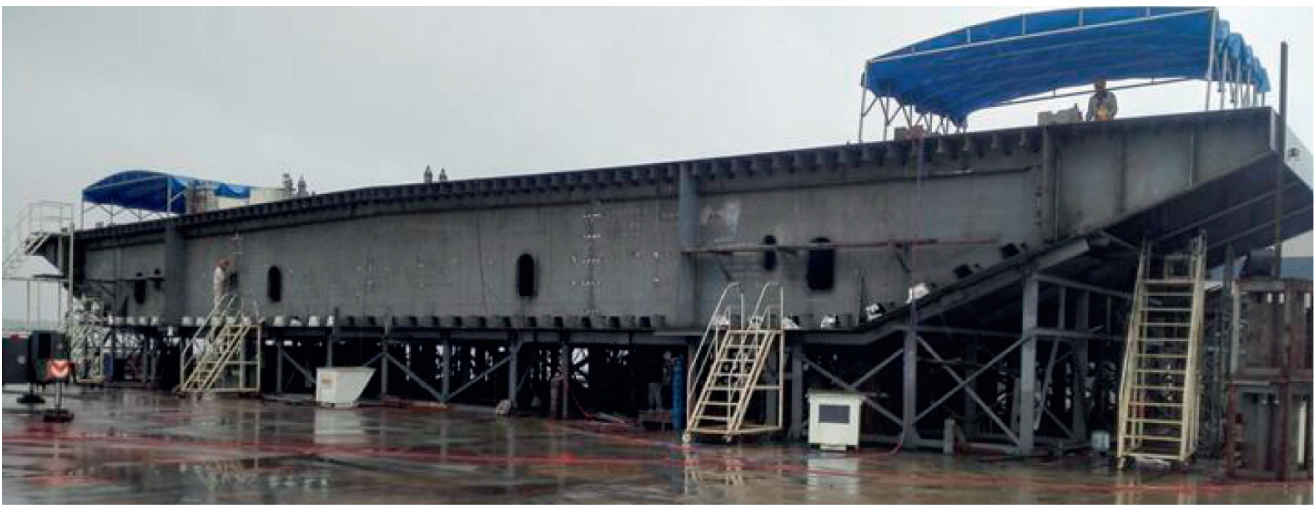

(b)

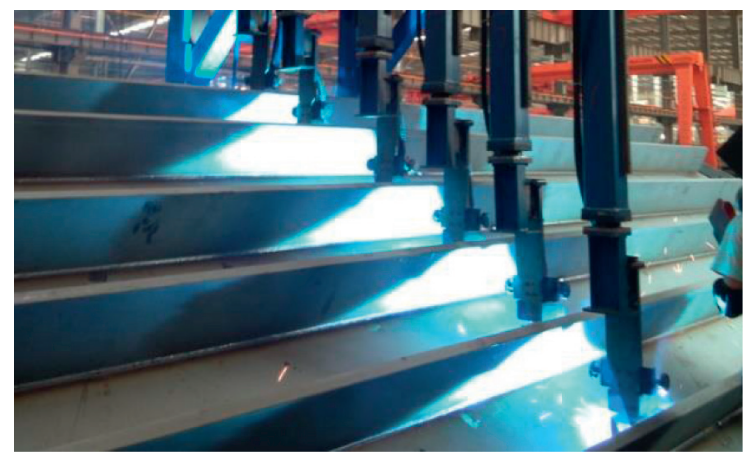

(c)

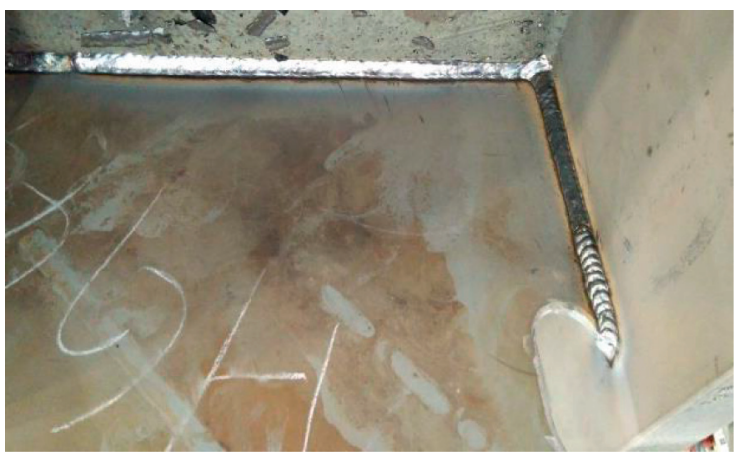

(d)

Figure 3: Design of steel box girder: (a) cross section of the steel box girder; (b) section diagram of the steel box girder; (c) bulb flat ribs welding; (d) diaphragm-bulb flat rib weld (unit: $\mathrm{mm}$ ). 


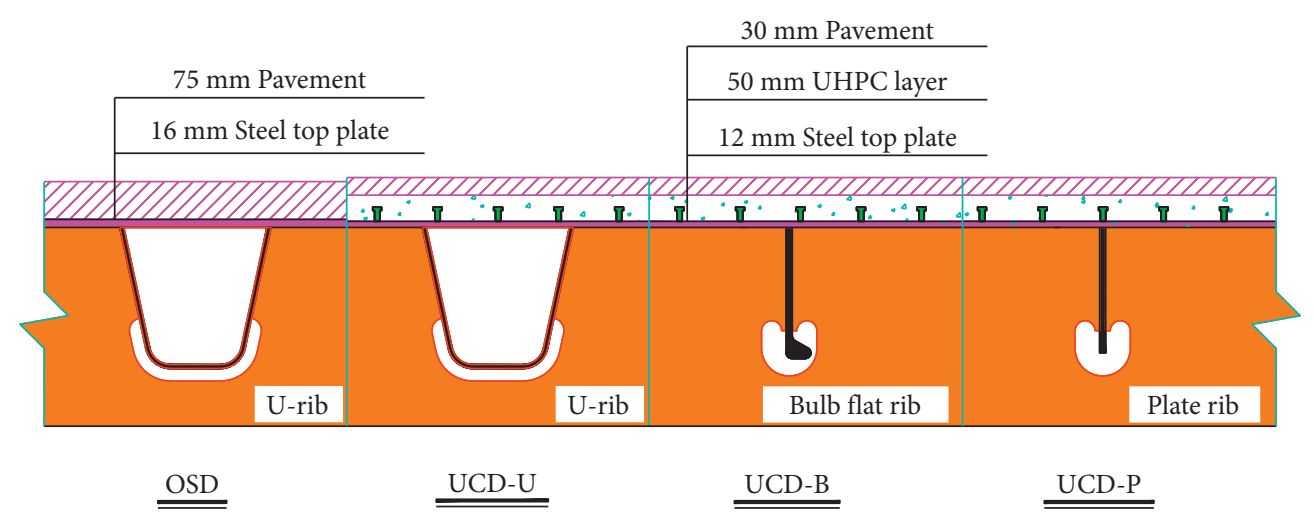

Figure 4: Four types of bridge deck schemes.

composite deck structures with different deck stiffness. However, the steel consumption of these three schemes is higher than that of Scheme 2, and the rigidity of the bridge deck structure is generally small, and the weight of the bridge deck structure increases greatly. According to the above comparison, the rigidity of the UCD-B is in the middle of UCD-U and OSD; its steel consumption is consistent with that of the UCD-U; its weight of the bridge deck structure is consistent with UCD-U and OSD. Therefore, the composite bridge deck with bulb flat ribs is a reasonable and feasible bridge deck structure.

According to the comparison of indexes in Schemes 3 to 5 , all indexes of the bridge deck in Scheme 4 are relatively balanced, so Scheme 4 is recommended as the design scheme of composite bridge deck with bulb flat ribs. In order to further verify the bearing capacity and fatigue performance of the composite deck with bulb flat ribs, a detailed study is conducted on the load-carrying capacity and fatigue performance of the composite deck, elaborated in the following part.

\section{Load-Carrying Capacity}

4.1. Finite Element Model. The finite element model of the steel box girder is established by the software ANSYS. In order to simulate the stress of the main girder and reduce the influence of boundary conditions, eight standard segments $(21.6 \mathrm{~m})$ of steel box girder are selected to establish a finite element model. In the model, the steel structure is simulated by the element Shell 63, and the UHPC layer by the element Solid 45. The boundary conditions of the FE model were as follows: (1) the steel anchor box should be subject to vertical restraint; (2) some lifting points should be subject to transverse and longitudinal restraint.

The FEA in this study did not account for the material nonlinearity of the UHPC, and the reasons are as follows: on the one hand, experimental investigations revealed that the reinforced UHPC exhibited high cracking strength (i.e., 42.7 $\mathrm{MPa}$ ) and, on the other hand, their theoretical analyses indicated that the maximum tensile stress of the UHPC layer was only $13.1 \mathrm{MPa}$ under design traffic loads, much less than its cracking strength. Thus, the UHPC layer is assumed to behave in the linear-elastic range. The elastic modulus and Poisson's ratio of UHPC were $42.6 \mathrm{GPa}$ and 0.2 , respectively. The steel material of the box girder is $\mathrm{Q} 345 \mathrm{qD}$, a steel grade for bridges in China that has an yield strength of $345 \mathrm{MPa}$. The model is shown in Figure 5.

4.2. Loading. The static strength calculation of the box girder considers the effects of constant load and live load of vehicles. According to China code (JTG D60-2004), the vehicle load is $550 \mathrm{kN}$ standard vehicle, and the impact factor is considered as 1.3. The vehicle load dimensions are shown in Figure 6.

Figure 7 shows the arrangement of loading. Under the vehicle load, the stress distribution of the orthotropic plate is local, while the vehicle wheelbase is long. In order to simplify the calculation, only two $140 \mathrm{kN}$ rear axles of the vehicle are considered for loading. The longitudinal arrangement of the vehicle load is as follows: (a) loading middle of sling diaphragm; (b) loading across common diaphragm; and (c) loading across sling diaphragm.

The transverse loading arrangement of the vehicle is as follows: (a) loading above the longitudinal rib; (b) loading between longitudinal ribs; and (c) loading along the web of longitudinal rib, as shown in Figure 8. Considering the combination of three kinds of longitudinal loading and three kinds of transverse loading, a total of nine loading conditions are calculated for the deck system.

\section{Results and Discussion}

Table 2 summarizes the results of the nine loading conditions. The results include the deck deflection, UHPC principal tensile stress, top plate stress, longitudinal rib stress, and diaphragm stress of the three deck systems. According to the mechanical characteristics of three bridge deck schemes, some observations are summarized as follows: (1) UCD-B and UCD-U have little difference in the deck stiffness, which is larger than that of the OSD. (2) The stress of steel structure in UCD-U and UCD-B is significantly lower than that in OSD. (3) The structural stress level of UCD-B is the same as that of UCD-U, but the stress of some positions is lower than that of UCD-U. 


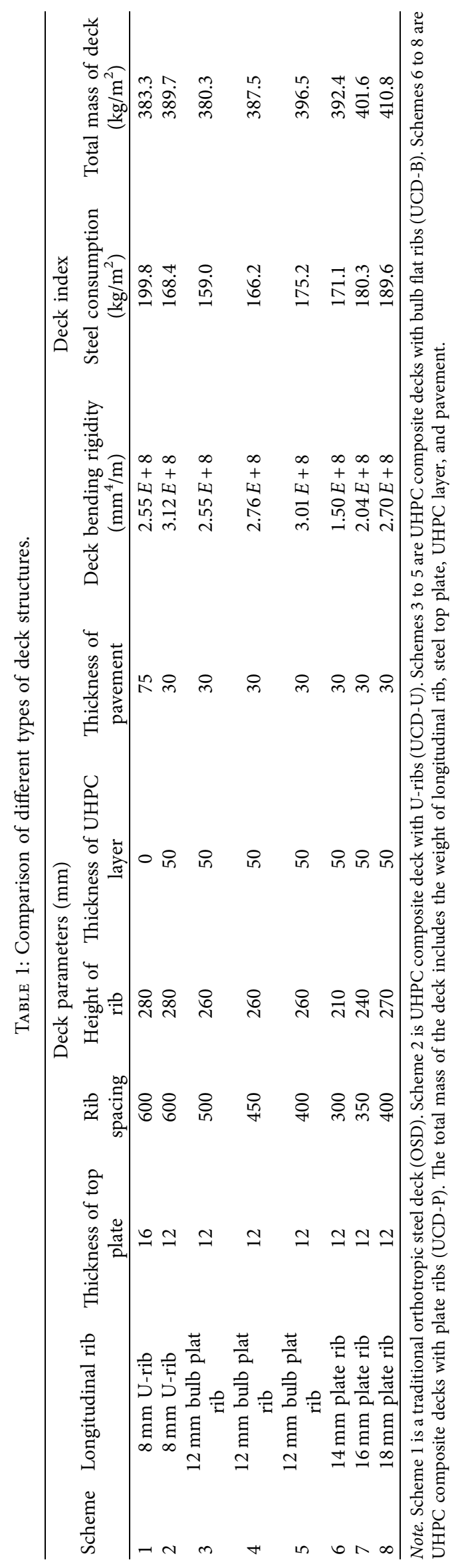




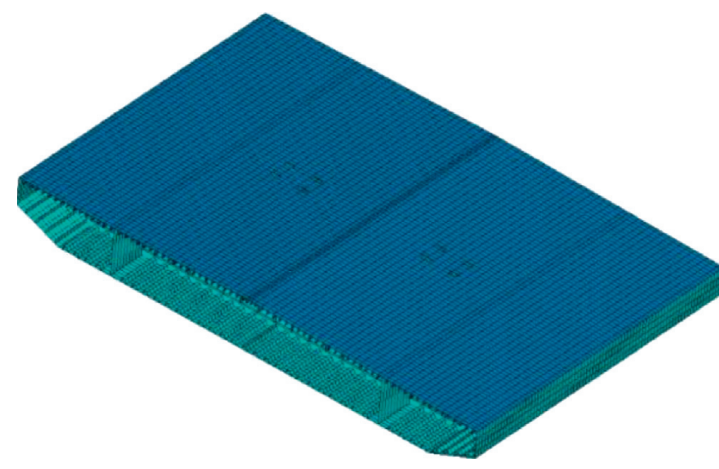

(a)

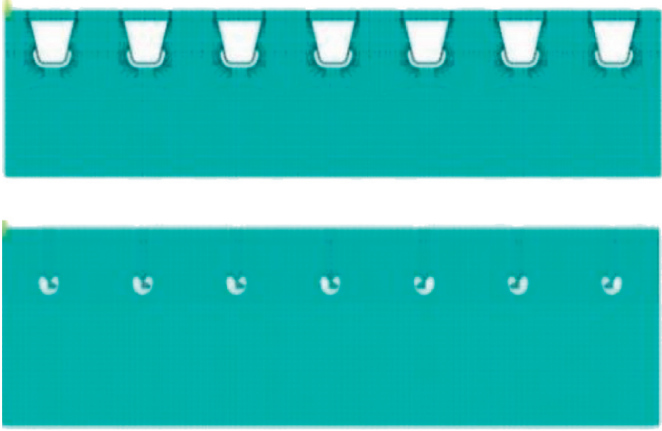

(b)

FIGURE 5: Finite element model of the OSD: (a) iso view; (b) cross sections.

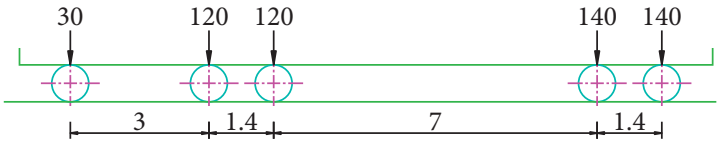

(a)

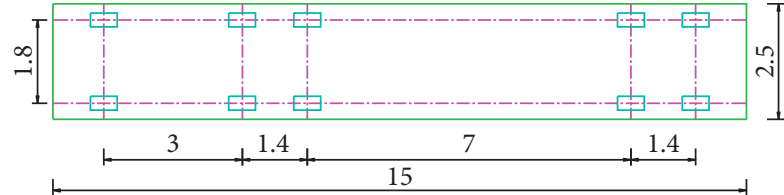

(b)

FIGURE 6: Depiction of the vehicle load for the load-carrying capacity: (a) elevation view; (b) top view (unit: meter for length and kN for force).

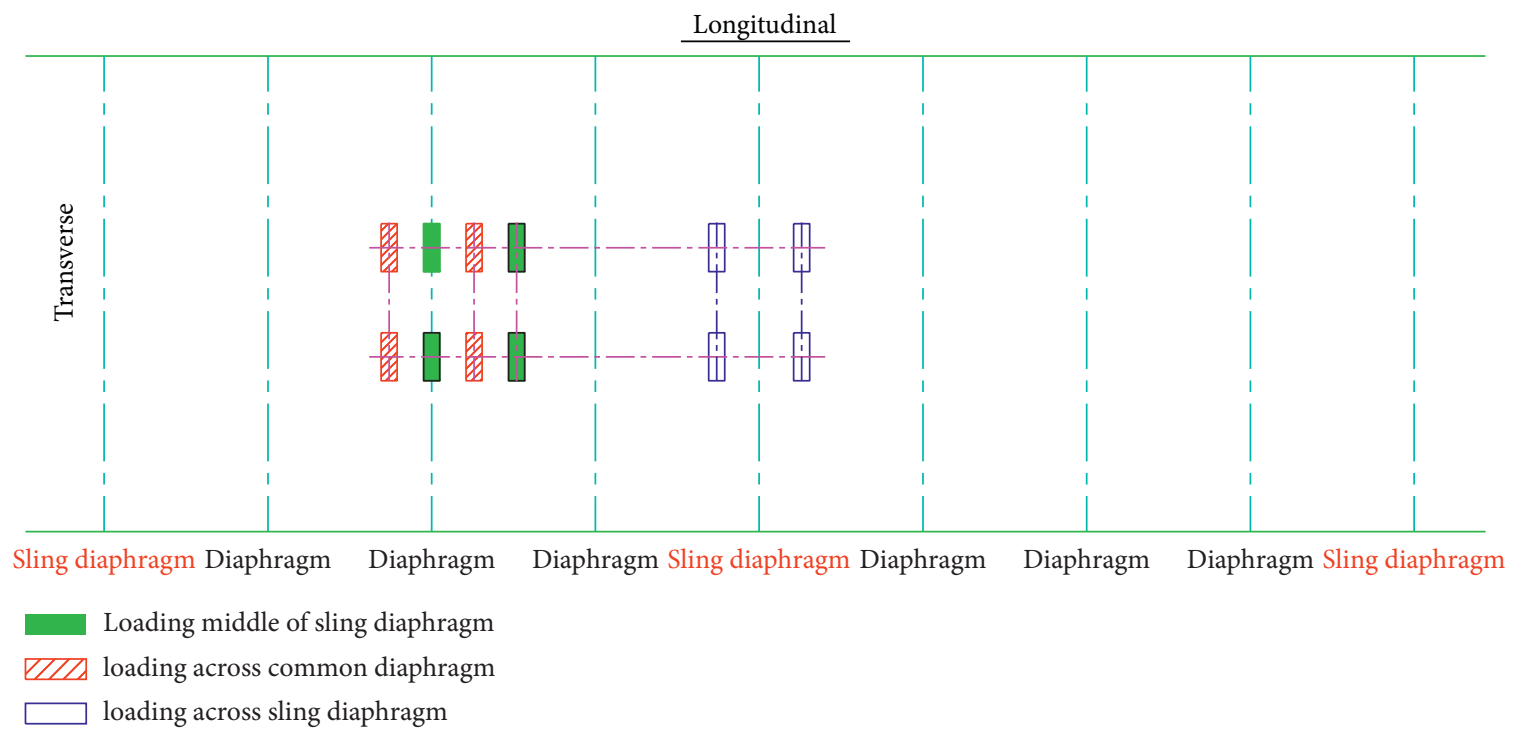

FIgURE 7: Longitudinal loading arrangement.

\section{Fatigue Performance}

6.1. Fatigue Load and Details. In this study, the standard single-vehicle load model of fatigue vehicle in China code (JTG D64-2015) is adopted for applying fatigue loading, as shown in Figure 9. The vehicle has four axles, and the weight of each axle is $120 \mathrm{kN}$, so the total weight of the vehicle is $480 \mathrm{kN}$, regardless of the impact factors. In order to facilitate calculation and improve the computational efficiency, only two rear axles are used for the loading in this study. Besides, the coupling effect of the front and the rear axles is not considered in this study.

Four fatigue details are selected for calculation and comparison, with the location of fatigue details as displayed in Figure 10. The diaphragm at the middle lifting point is taken as the checking diaphragm for the four fatigue details, and subsequent adverse loading is carried out for the fatigue details on the checking diaphragm. 


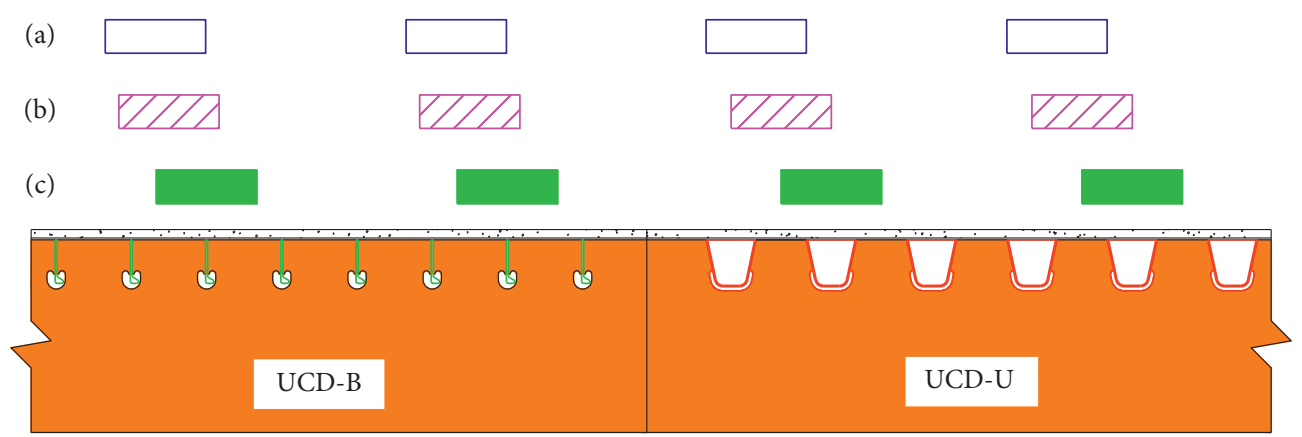

FIGURE 8: Transverse loading arrangement: (a) loading along the web of longitudinal ribs; (b) loading between the longitudinal ribs; (c) loading above the longitudinal ribs.

TABle 2: Deflection and stress of the bridge deck under dead load and live load.

\begin{tabular}{lccccc}
\hline Scheme & $\begin{array}{c}\text { Deflection } \\
(\mathrm{mm})\end{array}$ & $\begin{array}{c}\text { Principal tensile stress of } \\
\text { UHPC }(\mathrm{MPa})\end{array}$ & $\begin{array}{c}\text { Principal tensile stress of top } \\
\text { plate }(\mathrm{MPa})\end{array}$ & $\begin{array}{c}\text { Stress of diaphragm } \\
(\mathrm{MPa})\end{array}$ & $\begin{array}{c}\text { Stress of longitudinal } \\
\text { rib }(\mathrm{MPa})\end{array}$ \\
\hline OSD & 23.8 & - & 122.4 & 225.1 & 263.7 \\
UCD-U & 21.8 & 13.1 & 51.1 & 158.4 & 154.4 \\
$\begin{array}{l}\text { UCD-B } \\
\text { (scheme 4) }\end{array}$ & 22.1 & 12.0 & 53.8 & 116.0 & 154.7 \\
\hline
\end{tabular}

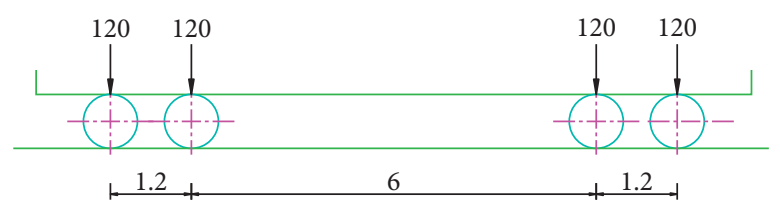

(a)

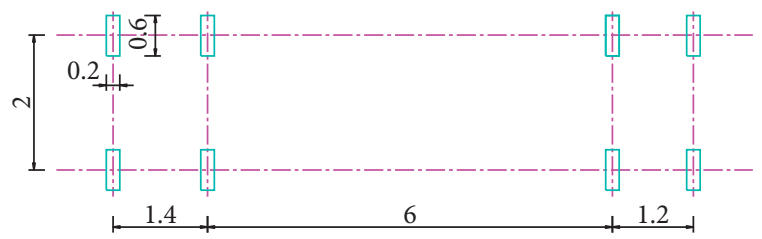

(b)

FIgURE 9: Layout of vehicle load for fatigue testing: (a) elevation view; (b) top view (unit: meter for length and $\mathrm{kN}$ for force).

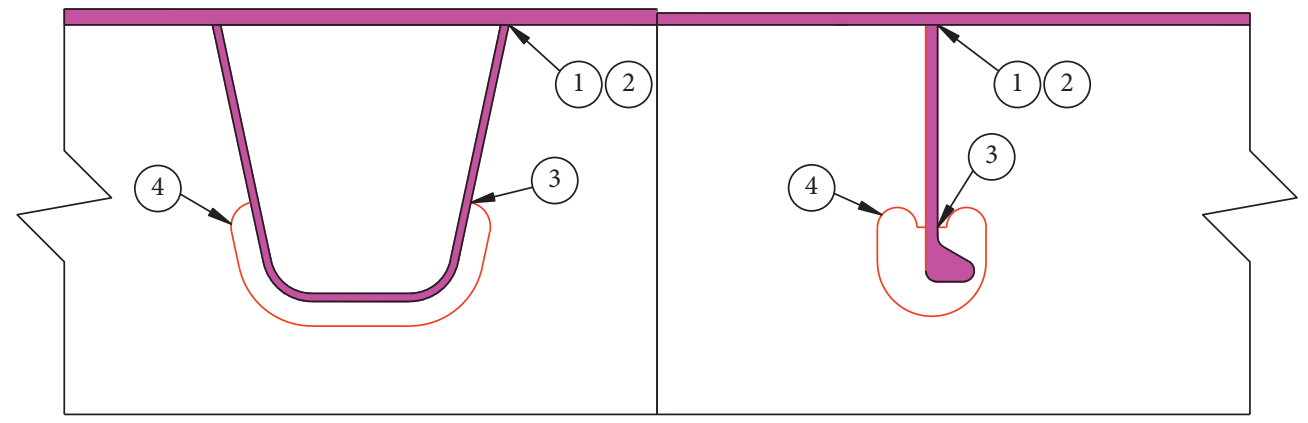

FIgURe 10: Fatigue detail.

\subsection{Loading Types}

6.2.1. Transverse Loading. Eurocode 3 stipulates that the fatigue driving trace is distributed in the area of $0.25 \mathrm{~m}$ around the center line of the lane at a certain frequency. To determine the most unfavorable position of the transverse direction of the axle, the wheel load is placed at $0.25 \mathrm{~m}$ to the left of the lane center line at first as the starting point and then moved $0.1 \mathrm{~m}$ to the right each time. Subsequently, the stress conditions at each loading point are calculated, respectively, with each fatigue detail corresponding to 6 load conditions. According to the calculation results of 6 working conditions of each fatigue detail, the most unfavorable transverse loading position is determined. The transverse loading is shown in Figure 11.

6.2.2. Longitudinal Loading. After determining the most unfavorable transverse loading position, the wheel action is kept unchanged at this position. The front axle of the standard fatigue vehicle driving direction is taken as the starting point at the distance of $3.3 \mathrm{~m}$ from the checking calculation diaphragm, with taking every $0.3 \mathrm{~m}$ forward movement as a working condition, which gradually loads to 


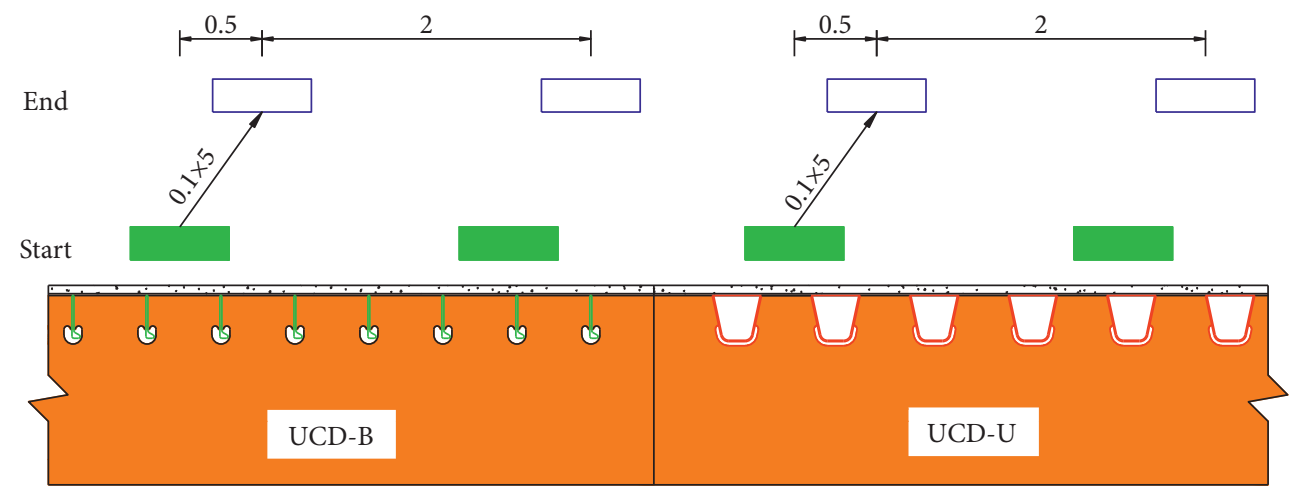

Figure 11: Transverse loading (unit: $\mathrm{m}$ ).

$3.3 \mathrm{~m}$ of the checking calculation diaphragm at the rear axle distance as the end. Each fatigue detail corresponds to 23 load cases. The longitudinal direction is shown in Figure 12.

6.3. Results and Discussion of Finite Element Analysis. According to the 23 longitudinal loading conditions corresponding to each fatigue detail, the most unfavorable fatigue stress amplitude of each detail is extracted. Specific data are shown in Table 3. The comparison conclusion is as follows:

(1) The stress amplitude of each fatigue detail in UCD-U and UCD-B is significantly lower than that in OSD, indicating that the UHPC composite deck is effective for avoiding fatigue failure.

(2) Compared with UCD-U, UCD-B shows a larger drop in fatigue stress and better fatigue performance in each fatigue detail.

\section{Fatigue Test}

7.1. Specimen, Test Setup, and Instrumentation. Figure 13 shows the specimen for the model tests. The overall dimensions of the specimen are $5500 \mathrm{~mm} \times 3150 \mathrm{~mm} \times 1062 \mathrm{~mm}$ (length $\times$ width $\times$ height), including two diaphragms and seven bulb flat ribs, with the spacing of $450 \mathrm{~mm}$. The bulb flat rib is $260 \mathrm{~mm}$ in height and $12 \mathrm{~mm}$ in thickness, and the top plate of the deck is $12 \mathrm{~mm}$ in thickness. The steel material of these components is Q345qD, a steel grade for bridges in China that has a yield strength of $345 \mathrm{MPa}$. Shear studs are welded on the steel top plate, with steel mesh being laid, and a $50 \mathrm{~mm}$ thick UHPC layer is poured at last, consistent with the prior studies [17-20]. The UCD-B is formed by high-temperature steam curing.

Figure 14(a) shows the test model and the setup. The specimen is supported by two rigid steel beams that are anchored on the strong floor, and it is loaded using a hydraulic actuator (capacity: $500 \mathrm{kN}$ ) fixed on a rigid steel frame. According to the finite element analysis results, the stress amplitude of the welding toe between diaphragm and stiffener (see Detail 3 in Figure 10) of the UCD-B is the largest, so the fatigue test focuses on the position. A steel plate measured as $600 \mathrm{~mm} \times 200 \mathrm{~mm}$ is placed between the actuator and the specimen to simulate the uniformly distributed wheel load. A rubber pad is placed between the steel base plate and the steel top plate as the energy-absorbing material. According to the finite element analysis, the maximum tensile stress amplitude at the weld toe of the diaphragm-to-rib welded joint is $67 \mathrm{MPa}$. This full-scale model test is intended to study the fatigue characteristics of this fatigue detail under the action of 1.3 times of stress amplitude $87 \mathrm{MPa}$ $(1.3 \times 67 \mathrm{MPa}=87 \mathrm{MPa})$. Figure $14(\mathrm{~b})$ shows the deployment of the strain gauges at the weld toe of the diaphragmto-rib welded joint.

7.2. Results and Discussion of the Fatigue Test. In this test, 2.5 million loads are applied under the action of 1.3 times the fatigue stress amplitude of the real bridge, and the overload fatigue performance of the test model in the long service life under the design stress amplitude is studied. During the test, when the number of load cycles is $0,0.1$ million, 0.5 million, 1.0 million, 1.5 million, 2 million, and 2.5 million, the fatigue loading is paused, and a static load test is performed. The static loading results of detail 3 after each cycle are as follows: 86.8 $\mathrm{MPa}$ (0), 89.4 MPa (0.5 million), 91.2 MPa (1 million), 89.7 MPa (1.5 million), 90.8 MPa (2 million), and $92.6 \mathrm{MPa}$ (2.5 million). Through the static load test and model inspection, no fatigue crack or slip is found at the fulcrum. Moreover, the whole composite bridge deck structure is intact.

According to the $\mathrm{S}-\mathrm{N}$ describing the fatigue performance of the structure, any stress amplitude and the corresponding number of cycles are satisfied: $\sigma_{i}^{m} N_{i}=C$, where $m$ and $C$ are constants related to the material and structural details and $\sigma_{i}$ and $N_{i}$ are equivalent stress amplitude and equivalent cycle times, respectively. If the structural design stress amplitude is $\sigma^{\prime}$, and the number of cycles is $N^{\prime}$; then, according to the Miner linear cumulative damage criterion $\sum\left(n_{i} / N_{i}\right)=1, N_{\mathrm{i}}$ can be expressed as $N_{i}=\left(\sigma^{\prime} / \sigma_{i}\right)^{m} N^{\prime}$. According to the code, if $m=3$, which is conservative, the number of cycles corresponding to the design stress amplitude $(67 \mathrm{MPa})$ is 5.5 million. 


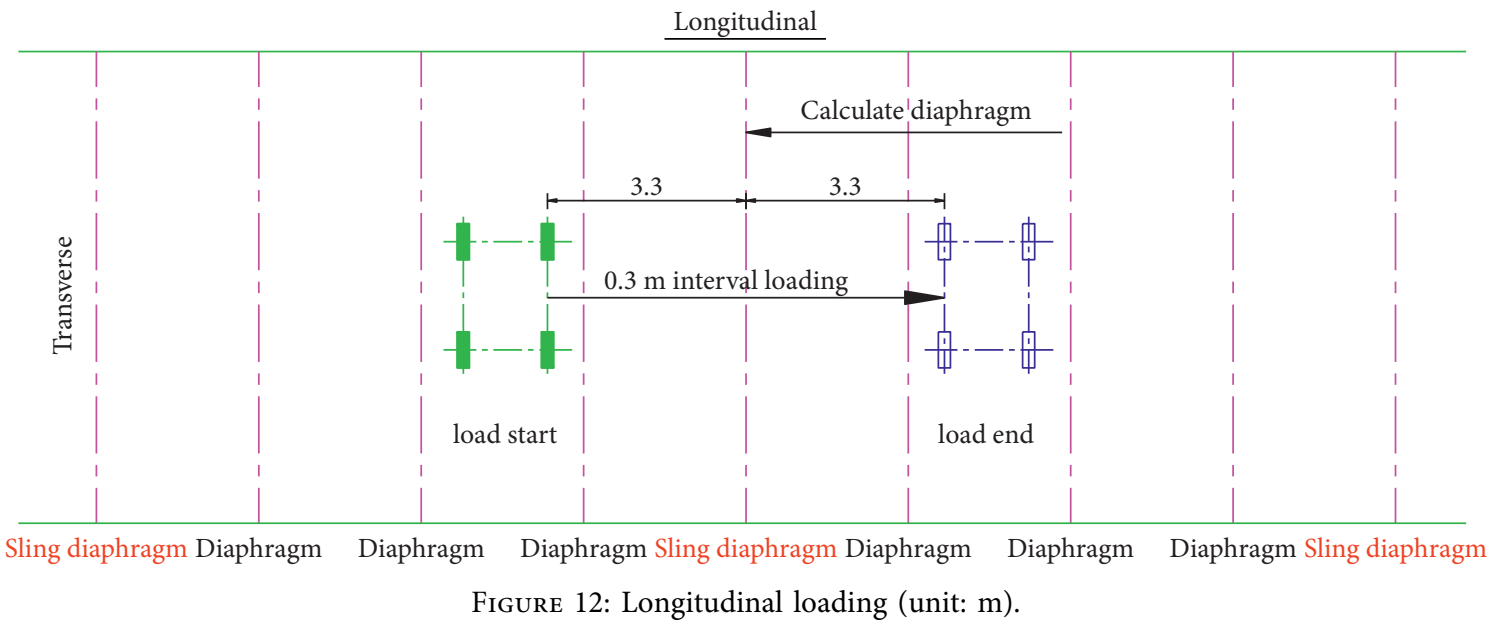

TABle 3: Maximum stress amplitude of each detail (unit: MPa).

\begin{tabular}{|c|c|c|c|c|c|c|}
\hline \multirow[b]{2}{*}{ Scheme } & \multicolumn{4}{|c|}{ Stress amplitude } & \multicolumn{2}{|c|}{ UHPC } \\
\hline & $\begin{array}{c}\text { Detail } 1 \\
\text { SX }\end{array}$ & $\begin{array}{c}\text { Detail } 2 \\
\text { SY }\end{array}$ & $\begin{array}{c}\text { Detail } 3 \\
\text { S1 }\end{array}$ & $\begin{array}{c}\text { Detail } 4 \\
\text { S1 }\end{array}$ & SX & SY \\
\hline (1) OSD & 95 & 161 & 132 & 96 & - & - \\
\hline (2) UCD-U & 28.6 & 34.4 & 74 & 77 & 1.7 & 8.1 \\
\hline (2) Decrease compared with (1) & $70 \%$ & $79 \%$ & $44 \%$ & $20 \%$ & - & - \\
\hline (3) UCD-B & 10.5 & 21.9 & 67 & 55 & 2.3 & 8.2 \\
\hline (3) Decrease compared with (1) & $89 \%$ & $86 \%$ & $49 \%$ & $43 \%$ & - & - \\
\hline
\end{tabular}

Note. SX is the transverse normal stress of bridge. SY is the longitudinal normal stress of bridge. S1 is the principal stress.

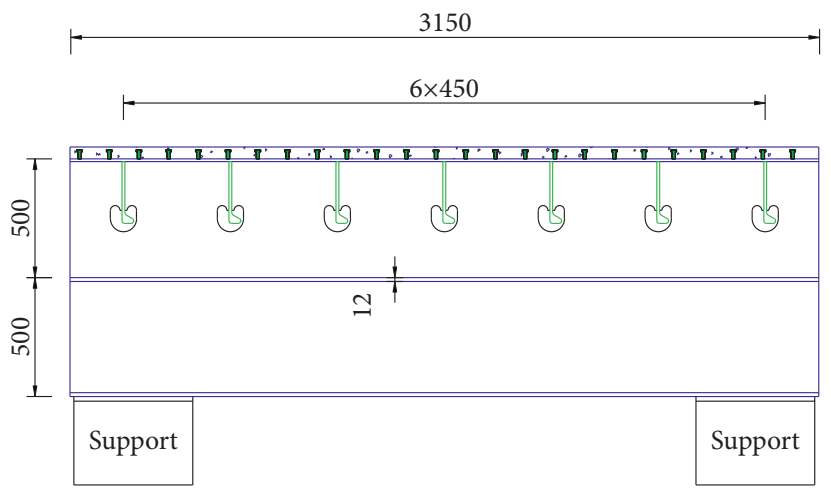

(a)

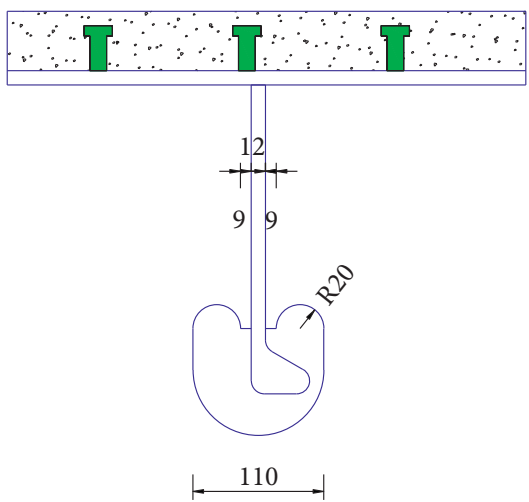

(b)

FIGURE 13: Full-scale specimen: (a) elevation view; (b) cross section (unit: mm).

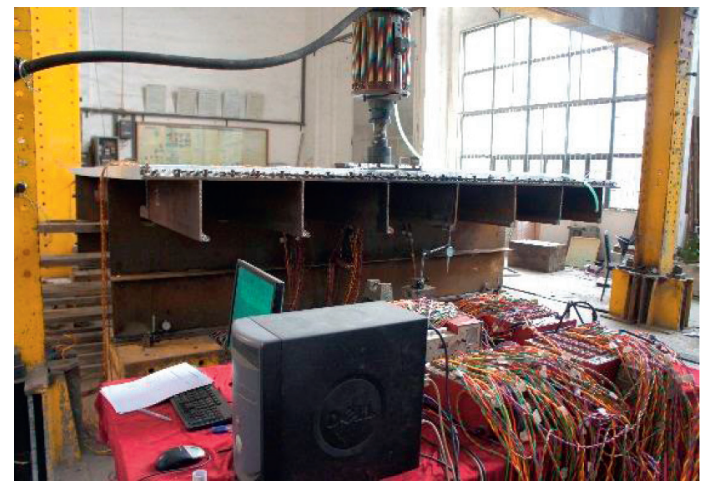

(a)

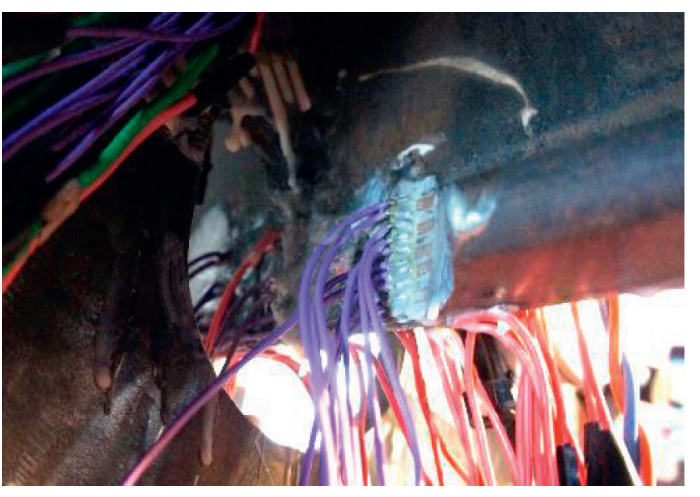

(b)

Figure 14: Fatigue test: (a) the specimen and test setup; (b) the strain gauges deployed on the tested specimen. 


\section{Conclusions}

In this study, a new composite deck structure with bulb flat steel and UHPC is proposed. The load-carrying capacity and fatigue performance of the composite deck are fully studied by FEA and model tests. Based on the research, the following conclusions are obtained:

(i) Through the preliminary comparison of four kinds of bridge deck structures, UCD-P has large steel consumption, self-weight, and low deck stiffness, so it is not a suitable stiffener for composite bridge deck; UCD-B shares the basically same steel consumption and deck weight as UCD-U, with slightly smaller deck stiffness, so it is a reasonable stiffener form for the composite bridge deck.

(ii) The FEA calculation results of three kinds of bridge deck structures reveal that the rigidity of UCD-B is in the middle of UCD-U and OSD, while the stress of UCD-B is the smallest among these three schemes, and the bearing capacity of the deck meets the design requirements.

(iii) The FEA calculation results of three kinds of bridge deck structures indicate that the fatigue stress amplitude of the composite bridge deck is lower than that of the orthotropic steel bridge deck, and the fatigue stress amplitude of UCD-B is the smallest, so its fatigue performance is the best.

(iv) The fatigue test is carried out on a UCD-B panel specimen. Under the action of 1.3 times the fatigue stress amplitude of the real bridge, no fatigue crack is observed in the steel structure and UHPC, after experiencing 2.5 million cycles.

\section{Data Availability}

The data used to support the findings of this study are available from the author Xiugui Sun (xgsun2013@hnu.edu.cn) upon request.

\section{Conflicts of Interest}

The authors declare no conflicts of interest.

\section{Acknowledgments}

This research was funded by the Natural Science Foundation of Hunan Province (grant no. 2021JJ50143), Hunan Science and Technology Talent Promotion Project (grant no. 2019TJ-Y08), and the Hunan Education Department Foundation Funded Project of China (grant nos. 21B0713 and 18A401). This study has received the help of Dr. Bao Y in the preparation of papers and data collation.

\section{References}

[1] Federal Highway Administration (Fhwa), US Department of Transportation. Manual for Design, Construction and Maintenance of Orthotropic Steel Deck Bridges, Books Express Publishing, Berkshire, UK, pp. 2-23, 2012.
[2] Q. H. Zhang, Y. Z. Bu, and Q. Li, "Review on fatigue problems of orthotropic steel bridge deck," China Journal of Highway and Transport, vol. 30, no. 3, pp. 14-30, 2017.

[3] Z. Xiang, Z. Zhu, Y. Huang, and T. Wang, "FEM analysis on fatigue cracking mechanism of diaphragm cutout in orthotropic steel decks," in Proceedings of the ASCE/The 4th orthotropic bridge conference proceedings, pp. 125-136, Tianjin, China, September 2015.

[4] Z. W. Zhu, Y. Huang, and Z. Xian, "Fatigue performance of floorbeam cutout detail of orthotropic steel bridge on heavy freight transportation highway," China Journal of Highway and Transport, vol. 30, no. 3, pp. 104-112, 2017.

[5] Y. Bao, W. Meng, Y. Chen, G. Chen, and K. H. Khayat, "Measuring mortar shrinkage and cracking by pulse prepump Brillouin optical time domain analysis with a single optical fiber," Materials Letters, vol. 145, pp. 344-346, 2015.

[6] Y. Bao, M. Valipour, W. Meng, K. H. Khayat, and G. Chen, "Distributed fiber optic sensor-enhanced detection and prediction of shrinkage-induced delamination of ultra-highperformance concrete overlay," Smart Materials and Structures, vol. 26, no. 8, Article ID 085009, 2017.

[7] Q. Zhang, Y. Liu, Y. Bao, D. Jia, Y. Bu, and Q. Li, "Fatigue performance of orthotropic steel-concrete composite deck with large-size longitudinal U-shaped ribs," Engineering Structures, vol. 150, pp. 864-874, 2017.

[8] Y. Liu, Q. Zhang, W. Meng, Y. Bao, and Y. Bu, "Transverse fatigue behaviour of steel-UHPC composite deck with large-size U-ribs," Engineering Structures, vol. 180, pp. 388-399, 2019.

[9] J. Qi, Y. Bao, J. Wang, L. Li, and W. Li, "Flexural behavior of an innovative dovetail UHPC joint in composite bridges under negative bending moment," Engineering Structures, vol. 200, Article ID 109716, 2019.

[10] W. Meng and K. H. Khayat, "Effect of hybrid fibers on fresh properties, mechanical properties, and autogenous shrinkage of cost-effective UHPC," Journal of Materials in Civil Engineering, vol. 30, Article ID 04018030, 2018.

[11] W. Meng and K. H. Khayat, "Mechanical properties of ultrahigh-performance concrete enhanced with graphite nanoplatelets and carbon nanofibers," Composites Part B: Engineering, vol. 107, pp. 113-122, 2016.

[12] W. Meng, M. Valipour, and K. H. Khayat, "Optimization and performance of cost-effective ultra-high performance concrete," Materials and Structures, vol. 50, no. 1, p. 29, 2017.

[13] W. Meng and K. H. Khayat, "Improving flexural performance of ultra-high-performance concrete by rheology control of suspending mortar," Composites Part B: Engineering, vol. 117, pp. 26-34, 2017.

[14] Z. W. Zhu, Y. Huang, P. X. Wen, W. Chen, Y. G. Shi, and $X$. D. Shao, "Investigation on fatigue performance of orthogonality bridge deck with steel-UHPC composite system under random traffic flows," China Journal of Highway and Transport, vol. 30, no. 3, pp. 200-209, 2017.

[15] S. Zhang, X. Shao, J. Cao, J. Cui, J. Hu, and L. Deng, "Fatigue performance of a lightweight composite bridge deck with open ribs," Journal of Bridge Engineering, vol. 21, no. 7, Article ID 04016039, 2016.

[16] Z. Zhu, T. Yuan, Z. Xiang, Y. Huang, Y. Zhou, and X. D. Shao, "Stress behaviors and fatigue performance of details in orthotropic steel bridges with UHPC-deck plate composite system under in-service traffic flows," Journal of Bridge Engineering, vol. 23, no. 3, pp. 1-21, 2018.

[17] B. A. Graybeal, Material Property Characterization of Ultrahigh Performance Concrete (No. FHWA-HRT-06-103), Federal 
Highway Administration, Office of Infrastructure Research and Development, McLean, VA, USA, 2006.

[18] A. Sriram, B. Petersen, and S. Sritharan, Design Guide for Precast UHPC Waffle Deck Panel System, Including Connections; FHWA-HRT-13-032, US Department of Transportation Federal Highway Administration, Washington, DC, USA, 2013.

[19] B. Graybeal, Design and Construction of Field-Cast UHPC Connections, United States Federal Highway Administration, McLean, VA, USA, 2014.

[20] M. Tohru and E. Brühwiler, "Tensile fatigue behaviour of ultrahigh performance fibre reinforced concrete (UHPCFR)," Materials and Structures, vol. 47, pp. 475-491, 2014. 